\title{
Axillary artery cannulation for veno-arterial extracorporeal membrane oxygenation support in cardiogenic shock
}

\author{
Suguru Ohira, MD, PhD, Ramin Malekan, MD, Joshua B. Goldberg, MD, Steven L. Lansman, MD, PhD, \\ David Spielvogel, MD, and Masashi Kai, MD, Collaborators
}

\section{ABSTRACT}

Objective: To review the outcomes of axillary artery $(A X)$ and femoral artery (FA) cannulation for veno-arterial extracorporeal membraneous oxygenation (VAECMO).

Methods: From 2009 to 2019, 371 patients who were supported with VA-ECMO for cardiogenic shock were compared based on the arterial cannulation site: $A X$ $(n=218)$ versus FA $(n=153)$.

Results: Patients in the AX group were older (61 years vs 58 years, $P=.011$ ), had a greater prevalence of peripheral vascular disease $(13.8 \%$ vs $5.2 \%, P=.008)$, and were less likely to have undergone cardiopulmonary resuscitation preoperatively ( $18.8 \%$ vs $36.6 \%, P<.001)$. Other characteristics were similar between groups, as were in-hospital outcomes, including survival to discharge ( $60.6 \%$ vs $56.9 \%)$, cerebrovascular accidents ( $12.4 \%$ vs $10.5 \%)$, cannulation-related bleeding $(15.1 \%$ vs $17 \%$ ), and length of VA-ECMO support ( 6 days). The incidence of leg ischemia $(6.9 \%$ VS $15.7 \%, P=.006)$, limb ischemia related to VA-ECMO cannulation (O\% vs $10.5 \%$ ), the need to switch the cannulation site ( $4.6 \%$ vs $14.7 \%$ ), and wound complications (WCS; $2.8 \%$ vs $15 \%$ ) including infection and additional procedure were significantly greater in the FA group $(P<.001)$. In multiple logistic regression analysis, FA cannulation and primary graft failure after heart transplantation were independent risk factors for cannulation-related WC. In subgroup analysis among patients with primary graft failure, WCs were more prevalent in FA cannulation (3.6\% vs $39.1 \%, P=.001)$.

Conclusions: AX cannulation for VA-ECMO is a safe and effective alternative to FA cannulation. It can be considered especially for patients with limited groin access, peripheral vascular disease, or for primary graft failure after heart transplant. (JTCVS Techniques 2021;5:62-71)

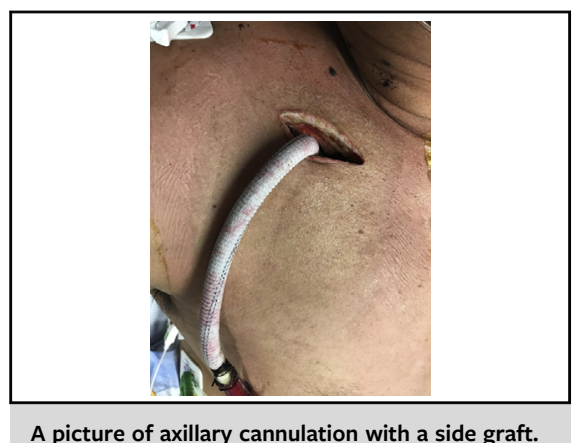

CENTRAL MESSAGE

Axillary artery cannulation for veno-arterial extracorporeal membrane oxygenation is safe and effective. It can be used as an alternative to femoral artery cannulation in cardiogenic shock.

\section{PERSPECTIVE}

Axillary artery ECMO provides equivalent efficacy to femoral artery ECMO in treating cardiogenic shock. In patients with peripheral vascular disease, limited groin access, high-risk for groin wound infection, or for primary graft failure after heart transplant, axillary artery cannulation may be an effective solution and with fewer complications compared with femoral artery access.

See Commentaries on pages 72 and 74 .
Video clip is available online.

From the Division of Cardiothoracic Surgery, Department of Surgery, Westchester Medical Center, New York Medical College, Valhalla, NY.

Collaborators: Philip J. Spencer, MD, ${ }^{\mathrm{a}}$ Avi Levine, MD, ${ }^{\mathrm{b}}$ Stephen Pan, MD, ${ }^{\mathrm{b}}$ Chhaya Aggarwal-Gupta, MD, ${ }^{b}$ Gregg M. Lanier, MD, ${ }^{b}$ Alan L. Gass, MD, ${ }^{b}$ Hasan Ahmad, MD, ${ }^{\mathrm{b}}$ Martin B. Cohen, MD, ${ }^{\mathrm{b}}$ and Srihari S. Naidu, $\mathrm{MD}^{\mathrm{b}}$

From the ${ }^{a}$ Division of Cardiothoracic Surgery, Department of Surgery, and ${ }^{b}$ Department of Cardiology, Westchester Medical Center, New York Medical College, Valhalla, NY.

Received for publication Oct 20, 2020; accepted for publication Oct 22, 2020; available ahead of print Nov 3, 2020.
Veno-arterial extracorporeal membrane oxygenation (VAECMO), which is increasingly used to support patients with severe cardiogenic shock, ${ }^{1}$ is expeditiously established via the femoral artery (FA) because of its accessibility.

Address for reprints: Masashi Kai, MD, Division of Cardiothoracic Surgery, Westchester Medical Center, New York Medical College, 100 Woods Rd, Macy Pavilion, Valhalla, NY 10595 (E-mail: Masashi.Kai@wmchealth.org). 2666-2507

Copyright (c) 2020 The Authors. Published by Elsevier Inc. on behalf of The American Association for Thoracic Surgery. This is an open access article under the CC BY-NCND license (http://creativecommons.org/licenses/by-nc-nd/4.0/).

https://doi.org/10.1016/j.xjtc.2020.10.035 


\section{Abbreviations and Acronyms \\ $\mathrm{AX} \quad=$ axillary artery \\ FA $\quad=$ femoral artery \\ PGF $\quad=$ primary graft failure \\ PVD $\quad=$ peripheral vascular disease \\ VA-ECMO $=$ veno-arterial extracorporeal membrane oxygenation}

Despite its usefulness, potential concerns of FA cannulation are retrograde arterial flow from the lower body and cannulation-related complications such as leg ischemia, bleeding, and infection, occurring in up to $35 \%$ of patients or more, which significantly impacts outcomes of VAECMO. $^{2-5}$ In addition, groin access to establish FA cannulation might be limited in patients with severe peripheral vascular disease (PVD) or indwelled temporary mechanical circulatory devices, which is frequently seen in a growing number of challenging patients. ${ }^{1}$ The axillary artery $(\mathrm{AX})$ can be an alternative arterial cannulation site that offers several potential benefits during VA-ECMO support: it is generally less calcified or diseased than the femoral vessels; it is less susceptible to infection due to it being less contaminated compared with groin and the presence of pectoral muscles; and it mostly provides antegrade flow to the systemic body. However, there is limited published experience with AX cannulation for patients with VA-ECMO, including our initial experiences. ${ }^{6-9}$ The aim of this study is evaluate the efficacy of AX cannulation and compare the outcomes with FA cannulation for VAECMO.

\section{METHODS}

A total of 420 patients were supported with VA-ECMO for cardiogenic shock from November 2009 to October 2019. Patients were divided into 2 groups in an intention-to-treat analysis: AX cannulation $(\mathrm{n}=218)$ and FA cannulation $(\mathrm{n}=153)$. Forty-nine patients who initially required central aortic cannulation $(n=28)$ or double arterial cannulation (axillary-axillary, or axillary-femoral, $\mathrm{n}=21$ ) were excluded from this study. Data were collected retrospectively by reviewing medical records and a prospectively maintained institutional database. The institutional review board of New York Medical College approved this study (approval number: \#14055; April 14, 2020). The implanting surgeon or interventional cardiologist determined the cannulation site according to their preference, patient's condition, and background (Figure 1, Video 1). Eighty-five percent of patients (313 patients) were cannulated by surgeons. An individual consent was waived due to the retrospective nature of this study.

\section{Cannulation Technique}

Our technique for right AX cannulation was previously reported. ${ }^{8}$ An incision is made parallel to the lateral two thirds of the clavicle. The pectoralis minor is retracted laterally. After administering the patient heparin to reach an activated coagulation time above 200 seconds, an 8- or 10-mm
Algorithm of selecting arterial cannulation site of

venoarterial extracorporeal membrane oxygenation

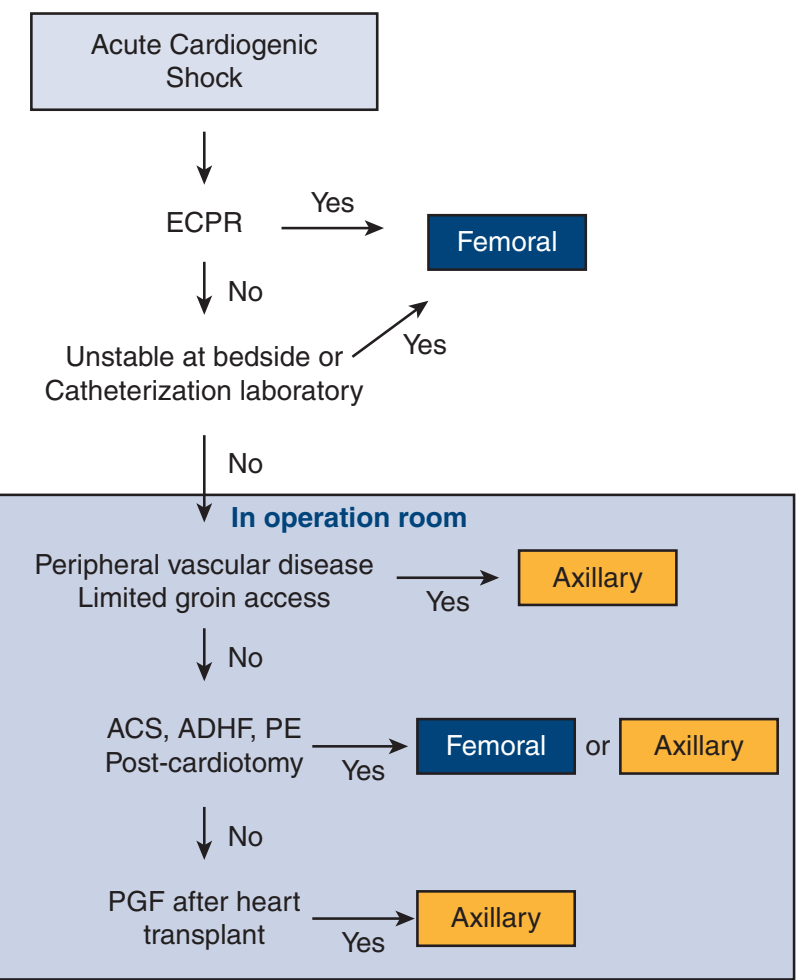

ACS: acute coronary syndrome; ADHF: acute decompensated heart failure; ECPR: extracorporeal cardiopulmonary resuscitation; PE: pulmonary embolism; PGF: primary graft failure

FIGURE 1. Our algorithm of determining an arterial cannulation site for veno-arterial extracorporeal membrane oxygenation. In case of ECPR, or if patients are at catheterization laboratory or unstable to transfer to an $\mathrm{OR}$, femoral artery cannulation is indicated. Axillary artery cannulation is indicated for patients with a limited groin access, peripheral vascular disease, or primary graft failure after heart transplant. For the rest of patients, an arterial cannulation site is determined by surgeons, either axillary or femoral artery. ECPR, Extracorporeal cardiopulmonary resuscitation; $A C S$, acute coronary syndrome; $A D H F$, acute decompensated heart failure; $P E$, pulmonary embolism; $P G F$, primary graft failure.

Dacron graft is anastomosed to the AX, using a running 5-0 polypropylene suture, and a small amount of Bio-glue (CryoLife Inc, Kennesaw, $\mathrm{Ga}$ ) is applied to the anastomotic site. The graft is routed directly from the wound and connected to the ECMO circuit with a 2-way connector, mitigating flow turbulence. With sterile, suction drainage applied, the wound and circuit are covered with a drape from the chest to the abdomen, and an elastic bandage is gently applied to the ipsilateral arm to enhance venous return.

Common FA cannulation was performed percutaneously, using a 15-Fr or 17-Fr arterial cannula, and distal limb perfusion was achieved by cannulating the superficial FA with a 6-Fr or 8-Fr wire-reinforced catheter whenever possible. Insertion of a distal perfusion catheter was attempted before insertion of a FA cannula. If a patient was prohibitively unstable, a FA 


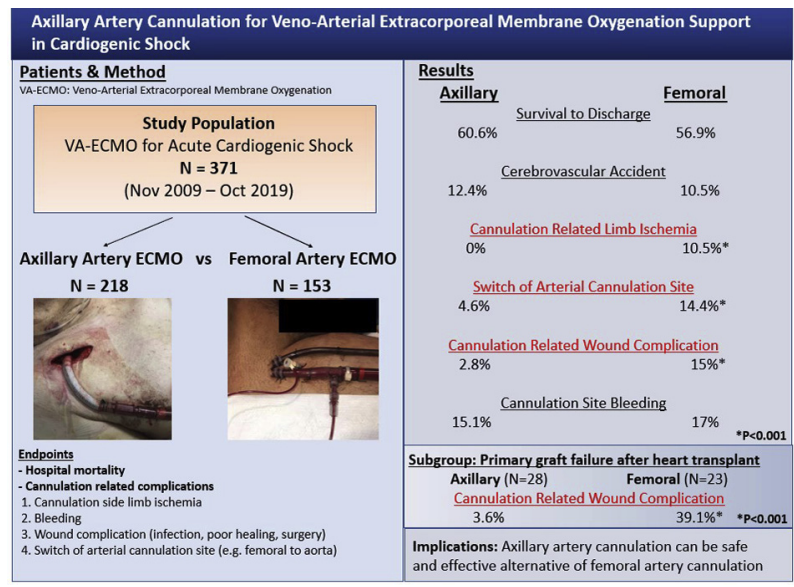

VIDEO 1. This study reviewed the outcomes of axillary artery (AX) and femoral artery (FA) cannulation for veno-arterial extracorporeal membrane oxygenation (VA-ECMO). Early outcomes were similar including survival to discharge, cerebrovascular accidents, and bleeding related to cannulation. The incidence of limb ischemia related to cannulation, the need to switch the cannulation site, and wound complications were significantly higher in the FA group. FA cannulation and primary graft failure (PGF) after heart transplantation were independent risk factors for cannulationrelated WC. In sub-group analysis among PGF patients after heart transplant, WC were more frequent in FA cannulation. Our algorithm of determining an arterial cannulation site for VA-ECMO. In case of ECPR, or if patients are at catheterization laboratory or prohibitively unstable to transfer to an OR, femoral artery cannulation is indicated. Axillary artery cannulation is indicated for patients with a limited groin access, peripheral vascular disease, or primary graft failure after heart transplant. For the rest of patients, an arterial cannulation site is determined by surgeons, either axillary or femoral artery. AX cannulation for VA-ECMO is a safe and effective alternative to FA cannulation. It can be considered especially for patients with limited groin access, peripheral vascular disease, or for primary graft failure after heart transplant. $A C S$, Acute coronary syndrome; $A D H F$, acute decompensated heart failure; $E C P R$, extracorporeal cardiopulmonary resuscitation; $O R$, operation room; $P E$, pulmonary embolism; $P G F$, primary graft failure; $V A-E C M O$, veno-arterial extracorporeal membrane oxygenation. Video available at: https://www.jtcvs.org/article/ S2666-2507(20)30621-0/fulltext.

cannula was inserted to initiate VA-ECMO followed by insertion of a distal perfusion cannula. Forty-seven patients $(30.7 \%)$ of 153 patients in the FA group did not have an antegrade distal perfusion catheter. In both AX and FA cannulation, the femoral vein was percutaneously cannulated with a 22or 23/25-Fr long cannula for venous drainage.

\section{Postcannulation Management}

A continuous heparin infusion was started within 48 hours, with a partial thromboplastin time goal of 40 to 60 seconds. Peripheral pulses were checked every 1 hour, and blood pressure was monitored via an arterial line in the femoral, radial, or AX. If possible, low ECMO flows were maintained, between 1.5 and $2.2 \mathrm{~L} / \mathrm{min} / \mathrm{m}^{2}$, which has a number of salutary effects: it reduces afterload, which reduces pulmonary congestion by enhancing cardiac ejection ${ }^{5}$; it helps avoid ipsilateral limb hyperperfusion; and it mitigates arterial line pressure of VA-ECMO, which helps to prevent bleeding at the arterial access site. FA decannulation was performed with an open cutdown technique. Generally, AX decannulation was performed by amputating the graft one centimeter from the anastomosis and oversewing or stapling the stump. The fascia, subcutaneous tissue, and skin was closed tightly.

\section{End Points}

The primary end point was cannulation-related complications (bleeding, limb ischemia, revision of cannulation site, wound complications), ipsilateral limb hyperperfusion, any leg ischemia, and cerebrovascular accident (stroke, hemorrhage). Secondary end points were the survival to discharge. Cannulation-related limb ischemia was defined as ischemia requiring any surgical procedure, including revision of the arterial/distal perfusion cannula, fasciotomy for compartment syndrome, gangrene, or amputation..$^{2-5}$ Cannulation-related wound complication was defined as infection or requirement of an additional surgical intervention, such as arterial repair, washout with or without vacuum-assisted closure, and muscle flap closure. Hyperperfusion was defined as a warm, hyperemic, edematous, or painful limb. ${ }^{7}$ Leg ischemia was defined as any ischemia requiring surgical intervention regardless of the ECMO site.

\section{Statistical Analysis}

Normally distributed data were presented as the mean \pm standard deviation, and non-normally distributed data were presented as the median (interquartile range) which were compared using the Student $t$ test or Mann-Whitney $U$ test depending on the distribution of data (Kolmogorov-Smirnov normality test). Preoperative values were the ones of immediate before cannulation. Categorical variables were expressed in percentages and were compared using the $\chi^{2}$ test or Fisher exact test for univariate analyses. For continuous variables in which the outcome relationships were not linear, cutoff points were determined to convert these into categorical variables before logistic analyses. Multivariate logistic regression analyses were used to calculate the odds ratio for cannulation-related wound complications. All pre-ECMO and procedurerelated variables that were considered as possible risk factors influencing the occurrence of wound complications were placed into the multivariate logistic regression analyses: these included cannulation site, male sex, body mass index, diabetes mellitus, indication of primary graft failure (PGF) after heart transplant, PVD, and creatinine. Variables in model were checked for collinearity using the variance inflation factor $(<10)$. Statistical analyses were performed using the IBM SPSS 24.0 (IBM Corp, Armonk, NY).

\section{RESULTS \\ Baseline Characteristics}

Patients in the AX group were older (61 vs 58 years, $P=.011)$, had a greater prevalence of PVD $(13.8 \%$ vs $5.2 \%, P=.008)$, and were less likely to have undergone cardiopulmonary resuscitation preoperatively $(18.8 \%$ vs $36.6 \%, P<.001$; Table 1$)$. Left ventricular ejection fraction was slightly lower in the FA group, but not significantly so $(P=.076)$. Otherwise, baseline characteristics were similar between groups, including the prevalence of comorbidities, pre-ECMO clinical status, indications for VA-ECMO, and the prevalence of pre-existing mechanical support at the time of VA-ECMO placement. Postcardiotomy shock was the leading indication for VA-ECMO in the AX group $(30.3 \%)$ whereas acute coronary syndrome was the most 
TABLE 1. Demographics

\begin{tabular}{|c|c|c|c|c|}
\hline & All $(N=371)$ & Axillary $(N=218)$ & Femoral $(N=153)$ & $P$ value \\
\hline Age, $y$ & $60(51-68)$ & $61(53-70)$ & $58(49-66)$ & .011 \\
\hline Male & $246(66.3 \%)$ & $139(63.8 \%)$ & $107(69.9 \%)$ & .216 \\
\hline Body surface area, $\mathrm{m}^{2}$ & $2.00 \pm 0.27$ & $1.99 \pm 0.26$ & $2.02 \pm 0.28$ & .209 \\
\hline Body mass index, $\mathrm{kg} / \mathrm{m}^{2}$ & $27.9(25.0-32.3)$ & $27.8(24.6-32.3)$ & $28.4(25.4-32.5)$ & .318 \\
\hline $\begin{array}{l}\text { Indication } \\
\text { Acute coronary syndrome } \\
\text { Postcardiotomy } \\
\text { Primary graft failure } \\
\text { Decompensated heart failure } \\
\text { Pulmonary embolism }\end{array}$ & $\begin{array}{c}109(29.4 \%) \\
100(27 \%) \\
51(13.7 \%) \\
94(25.3 \%) \\
17(4.6 \%)\end{array}$ & $\begin{array}{c}59(27.1 \%) \\
66(30.3 \%) \\
28(12.8 \%) \\
56(25.7 \%) \\
9(4.1 \%)\end{array}$ & $\begin{array}{c}50(32.7 \%) \\
34(22.2 \%) \\
23(15 \%) \\
38(24.8 \%) \\
8(5.2 \%)\end{array}$ & .447 \\
\hline Diabetes mellitus & $143(38.5 \%)$ & $88(40.4 \%)$ & $585(35.9 \%)$ & .389 \\
\hline Hypertension & $253(68.2 \%)$ & $152(69.7 \%)$ & $101(66 \%)$ & .450 \\
\hline Chronic lung disease & $39(10.5 \%)$ & $26(11.9 \%)$ & $13(8.5 \%)$ & .289 \\
\hline Cerebrovascular disease & $39(10.5 \%)$ & $26(11.9 \%)$ & $13(8.5 \%)$ & .289 \\
\hline Creatinine $\geq 1.5 \mathrm{mg} / \mathrm{dL}$ & $160(43.1 \%)$ & $93(42.7 \%)$ & $67(43.8 \%)$ & .829 \\
\hline Liver disease & $31(8.4 \%)$ & $19(8.7 \%)$ & $12(7.8 \%)$ & .765 \\
\hline Peripheral vascular disease & $38(10.2 \%)$ & $30(13.8 \%)$ & $8(5.2 \%)$ & .008 \\
\hline Ejection fraction, $\%$ & $24(15-41)$ & $28(17-45)$ & $20(15-35)$ & .076 \\
\hline Total bilirubin, $\mathrm{mg} / \mathrm{dL}$ & $1.0(0.6-1.6)$ & $1.0(0.6-1.6)$ & $1.0(0.6-1.6)$ & .641 \\
\hline Aspartate transaminase, $\mathrm{U} / \mathrm{L}$ & $76(30-333)$ & $68.5(32-247)$ & $96.5(28-504)$ & .538 \\
\hline Alanine transaminase, $\mathrm{U} / \mathrm{L}$ & $49(25-179)$ & $44(25-120)$ & $60.5(23.5-260)$ & .123 \\
\hline Lactate, $\mathrm{mmol} / \mathrm{L}$ & $5.4(2.8-9.5)$ & $5.3(2.4-9.2)$ & $6.2(3.1-10.1)$ & .166 \\
\hline Intra-aortic balloon pump & $181(48.8 \%)$ & $104(47.7 \%)$ & $77(50.3 \%)$ & .619 \\
\hline Impella & $44(11.9 \%)$ & $26(11.8 \%)$ & $18(11.9 \%)$ & .962 \\
\hline INTERMACS, profile I & $345(93 \%)$ & $200(91.7 \%)$ & $145(94.8 \%)$ & .261 \\
\hline Extracorporeal CPR & $39(10.5 \%)$ & $2(0.9 \%)$ & $37(24.2 \%)$ & $<.001$ \\
\hline Any CPR before ECMO & $97(26.1 \%)$ & $41(18.8 \%)$ & $56(36.6 \%)$ & $<.001$ \\
\hline
\end{tabular}

Values are expressed with $\mathrm{n}(\%)$, mean \pm standard deviation, or median (interquartile range). INTERAMACS, The Interagency Registry for Mechanically Assisted Circulatory Support; $C P R$, cardiopulmonary resuscitation; $E C M O$, extracorporeal membrane oxygenation.

common in the FA group $(32.7 \%)$, likely reflecting the ease of arterial access in the operating room versus the cardiac catheterization laboratory.

\section{In-Hospital Outcomes}

Overall, the rate of successful VA-ECMO explantation was $76 \%$ (282 patients) and survival to discharge was 59\% (219 patients; Table 2), with no significant differences between the AX and FA groups. The median length of ECMO support was 6 days. Of 282 patients successfully explanted, $222(78.7 \%)$ were bridged-torecovery, whereas $60(21.3 \%)$ required advanced heart failure therapy: $48(17 \%)$ required a ventricular assist device and $12(4.2 \%)$ underwent cardiac transplantation.
The incidence of atrial fibrillation was greater in the $\mathrm{AX}$ group $(18.3 \%$ vs $10.5 \%, P=.037)$. However, the rates of cerebrovascular accident, including intracranial hemorrhage and ischemic stroke while on VA-ECMO support, were comparable between groups. There was no significant difference between groups in the incidence of stroke on VA-ECMO $(4.1 \%$ vs $4.6 \%)$ or following ECMO explantation $(5.0 \%$ vs $2.0 \%)$ or in the time to stroke occurrence following explantation (3 days vs 5 days). Among 10 patients who had stroke in the FA group, $70 \%$ (7 patients) developed stroke on VAECMO, whereas the incidence of stroke was similar between on and off VA-ECMO in the AX group (Table 3). Prolonged ventilation ( $\geq 7$ days) was required in $63.3 \%$; 
TABLE 2. In-hospital outcomes

\begin{tabular}{|c|c|c|c|c|}
\hline & All $(\mathbf{N}=\mathbf{3 7 1})$ & Axillary $(\mathrm{N}=\mathbf{2 1 8})$ & Femoral $(N=153)$ & $P$ value \\
\hline Survival to discharge & $219(59 \%)$ & $132(60.6 \%)$ & $87(56.9 \%)$ & .477 \\
\hline $\begin{array}{c}\text { Successful ECMO } \\
\text { explantation }\end{array}$ & $282(76 \%)$ & $171(78.4 \%)$ & $111(72.5 \%)$ & .191 \\
\hline Bridge-to-recovery & $222 / 282(78.7 \%)$ & $140 / 171(81.9 \%)$ & $82 / 111(73.9 \%)$ & .182 \\
\hline Bridge-to-VAD & $48 / 282(17 \%)$ & $26 / 171(15.2 \%)$ & $22 / 111(19.8 \%)$ & \\
\hline Bridge-to-transplant & $12 / 282(4.2 \%)$ & $5 / 171(2.9 \%)$ & $7 / 111(6.3 \%)$ & \\
\hline Length of ECMO support, $d$ & $6(4-9)$ & $6(4-9)$ & $6(3-9)$ & .131 \\
\hline ECMO support $\geq 14 \mathrm{~d}$ & $48(12.9 \%)$ & $26(11.9 \%)$ & $22(14.4 \%)$ & .488 \\
\hline Cerebrovascular accident & $43(11.6 \%)$ & $27(12.4 \%)$ & $16(10.5 \%)$ & .568 \\
\hline Intracranial hemorrhage & $16(4.3 \%)$ & $9(4.1 \%)$ & $7(4.6 \%)$ & .835 \\
\hline Stroke & $30(8.0 \%)$ & $20(9.2 \%)$ & $10(6.5 \%)$ & .359 \\
\hline Stroke on ECMO & $16(4.3 \%)$ & $9(4.1 \%)$ & $7(4.6 \%)$ & .835 \\
\hline $\begin{array}{l}\text { Stroke after ECMO } \\
\text { explantation }\end{array}$ & $14(3.8 \%)$ & $11(5.0 \%)$ & $3(2.0 \%)$ & .208 \\
\hline Explantation to stroke, $\mathrm{d}$ & $4.5(1-12)$ & $3(1-7)$ & $5(4.5-113)$ & .912 \\
\hline Atrial fibrillation & $56(15 \%)$ & $40(18.3 \%)$ & $16(10.5 \%)$ & .037 \\
\hline Prolonged ventilation $\geq 7 \mathrm{~d}$ & $235(63.3 \%)$ & $136(62.4 \%)$ & $99(64.7 \%)$ & .648 \\
\hline Tracheostomy & $103(27.8 \%)$ & $65(29.8 \%)$ & $38(24.8 \%)$ & .292 \\
\hline Percutaneous gastrostomy & $29(7.8 \%)$ & $20(9.2 \%)$ & $9(5.9 \%)$ & .245 \\
\hline Renal-replacement therapy & $118(31.8 \%)$ & $63(28.9 \%)$ & $55(35.9 \%)$ & .151 \\
\hline Length of hospital stay, d & $32(16-68)$ & $32(17-66)$ & $32(12.5-70)$ & .401 \\
\hline
\end{tabular}

Values are expressed with $\mathrm{n}(\%)$, or mean \pm standard deviation, or median (interquartile range). ECMO, Extracorporeal membrane oxygenation; VAD, ventricular assist device.

TABLE 3. Timing and lesions of stroke

\begin{tabular}{lcc}
\hline & Axillary $(\mathbf{N}=\mathbf{2 1 8})$ & Femoral $(\mathbf{N}=\mathbf{1 5 3})$ \\
\hline Total stroke & 20 & 10 \\
On VA-ECMO & $9(45 \%)$ & $7(70 \%)$ \\
Left MCA & 2 & 3 \\
Left ICA & 0 & 1 \\
Left PCA & 1 & 0 \\
Right MCA & 3 & 1 \\
Right MCA + PCA & 2 & 0 \\
Right PCA & 0 & 1 \\
Bilateral multiple & 1 & 1 \\
After VA-ECMO & $11(55 \%)$ & $3(30 \%)$ \\
explantation & & \\
Left MCA & 1 & 2 \\
Left MCA + PCA & 0 & 1 \\
Left ICA & (focal dissection) & 0 \\
Right MCA & 5 & 0 \\
Right PCA & 1 & 0 \\
Right ICA & 2 & 0 \\
Bilateral MCA & 1 & 0 \\
Hospital mortality & $12 / 20(60 \%)$ & $5 / 10(50 \%)$ \\
\hline
\end{tabular}

Values are expressed with $\mathrm{n}(\%)$. VA-ECMO, Veno-arterial extracorporeal membrane oxygenation; $M C A$, middle cerebral artery; $I C A$, internal carotid artery; $P C A$, posterior cerebral artery. with tracheostomy required in $27.8 \%$; and renalreplacement therapy was required in $31.8 \%$, with no significant difference between groups.

\section{Cannulation-Related Outcomes}

Leg ischemia ( $6.9 \%$ vs $15.7 \%, P=.006)$, and cannulationrelated limb ischemia $(0 \%$ vs $10.5 \%, P<.001)$ were significantly lower in the AX group (Table 4). The incidence of leg ischemia not related to VA-ECMO cannulation was similar between groups of which a half of them caused by another device (Table 5). In the FA group, the incidence of limb ischemia was not significantly different between patients with (9 of 106 patients: $8.5 \%$ ) or without distal perfusion (7 of 47 patients: $14.6 \%)(P=.232)$. Bleeding was the leading cause of adverse events related to arterial cannulation in each group. The need to switch the cannulation site was greater in the FA group ( $4.6 \%$ vs $14.7 \%, P<.001)$, with $72.7 \%$ of the switches relocated to the AX and leg ischemia as the major indication of switching (59.1\%; Table 6). Switching to central aortic cannulation was performed in $10 \%$ of each group. The incidence of brachial plexus injury in the $\mathrm{AX}$ group was $0.9 \%$ (2 patients).

Wound complications, which mostly resulted from infection or poor wound healing, were lower in the group $\mathrm{AX}$ 
TABLE 4. Adverse events related to arterial cannulation

\begin{tabular}{|c|c|c|c|c|}
\hline & All $(N=371)$ & Axillary $(N=218)$ & Femoral $(N=153)$ & $P$ value \\
\hline Switch of cannulation site & $32(8.6 \%)$ & $10(4.6 \%)$ & $22(14.4 \%)$ & $<.001$ \\
\hline Cannulation site bleeding & $59(15.9 \%)$ & $33(15.1 \%)$ & $26(17 \%)$ & .630 \\
\hline Hyperperfusion & $5(1.3 \%)$ & $5(2.3 \%)$ & 0 & .153 \\
\hline Any leg ischemia & $39(10.5 \%)$ & $15(6.9 \%)$ & $24(15.7 \%)$ & .006 \\
\hline $\begin{array}{l}\text { Cannulation-related limb } \\
\text { ischemia }\end{array}$ & $16(4.3 \%)$ & 0 & $16(10.5 \%)$ & $<.001$ \\
\hline $\begin{array}{l}\text { Cannulation site wound } \\
\text { complication }\end{array}$ & $29(7.8 \%)$ & $6(2.8 \%)$ & $23(15 \%)$ & $<.001$ \\
\hline
\end{tabular}

( $2.8 \%$ vs $15.3 \%, P<.001$; Table 7$)$. Eleven $(47.8 \%)$ patients with FA cannulation required a sartorius muscle flap, including 1 patient who required repair of an infected artery, whereas patients with AX cannulation underwent less-invasive management procedures. In multiple logistic regression analysis, FA cannulation and PGF after heart transplant were significant risk factors for cannulationrelated wound complications (Table 8).

In a subgroup analysis among patients with PGF (Table 9), the incidence of cannulation-related wound complications was significantly lower in the $\mathrm{AX}$ group $(3.6 \%$ vs $39.1 \%$, $P=.001$ ), whereas survival to discharge was similar between the 2 groups ( $78.6 \%$ vs $82.6 \%, P=.994$; Table 10, Figure 2 ).

\section{DISCUSSION}

Early outcomes for patients with cardiogenic shock requiring VA-ECMO are still modest, with a reported survival to discharge rate of around $40 \% .^{1}$ In our singlecenter analysis comparing 2 different arterial access sites, overall rates of survival to discharge were favorable in both AX and FA access (60.6\% vs 56.9\%). Establishing secure arterial cannulation for VA-ECMO is important because complications of arterial cannulation such as bleeding or ischemia significantly impact on overall survival. ${ }^{10}$ In an emergent status such as extracorporeal cardiopulmonary resuscitation, FA cannulation is useful due to its quickness and accessibility. ${ }^{11}$ However, the fact is that data from Extracorporeal Life Support Registry Report showed approximately $75 \%$ of adult patients requiring VA-ECMO did not receive extracorporeal cardiopulmonary resuscitation. ${ }^{1}$ In this regard, a great number of patients in cardiogenic shock may have enough time to undergo AX cannulation in the operating room. There may be a concern regarding a longer procedure

TABLE 5. Detail of leg ischemia not related to ECMO cannulation

\begin{tabular}{lcc}
\hline & Axillary $(\mathbf{N}=\mathbf{2 1 8})$ & Femoral $(\mathbf{N}=\mathbf{1 5 3})$ \\
\hline Leg ischemia not related to & $15(6.9)$ & $9(5.9)$ \\
$\quad$ ECMO cannulation & & \\
Another cannula related & $7(46.7)$ & $5(55.6)$ \\
IABP side & 4 & 5 \\
Impella side & 2 & 0 \\
Arterial sheath & 1 & 0 \\
Others & $8(53.3)$ & $4(44.4)$ \\
Peripheral vascular disease & 5 & 0 \\
Heparin-induced & 1 & 1 \\
$\quad$ thrombocytopenia & & 3 \\
High dose of inotrope and/ & 2 & \\
$\quad$ or pressor & & \\
\hline
\end{tabular}

$\overline{\text { Values are expressed with } \mathrm{n}(\%) \text {. Some patients in femoral artery group experienced }}$ both cannulation-related leg ischemia and non-ECMO side leg ischemia. ECMO, Extracorporeal membrane oxygenation; IABP, intra-aortic balloon pump, Impella, percutaneous left ventricular assist device.

TABLE 6. Details of switch of arterial cannulation site

\begin{tabular}{lcc}
\hline & $\begin{array}{c}\text { Axillary } \\
(\mathbf{N}=\mathbf{1 0 / 2 1 8})\end{array}$ & $\begin{array}{c}\text { Femoral } \\
(\mathbf{N}=\mathbf{2 2} / \mathbf{1 5 3})\end{array}$ \\
\hline Switch to & & \\
$\quad$ Axillary & $1(10 \%)$ & $16(72.7 \%)$ \\
Femoral & $2(20 \%)$ & $2(9.1 \%)$ \\
Aorta & $1(10 \%)$ & $2(9.1 \%)$ \\
Bilateral axillary arteries & $2(20 \%)$ & $1(4.5 \%)$ \\
Axillary + femoral & $4(40 \%)$ & $1(4.5 \%)$ \\
Reason & & \\
Ischemia & 0 & $13(59.1 \%)$ \\
$\quad$ Ischemia without & & $4 / 13$ \\
$\quad$ distal perfusion & & $5(22.7 \%)$ \\
Bleeding & $5(50 \%)$ & $3(13.6 \%)$ \\
Inadequate flow & $5(50 \%)$ & $1(3.2 \%)$ \\
$\quad$ Promote ambulation & 0 &
\end{tabular}

Values are expressed as $\mathrm{n}(\%)$. 
TABLE 7. Details of cannulation site wound complication $(N=29)$

\begin{tabular}{lcc}
\hline & $\begin{array}{c}\text { Axillary } \\
(\mathbf{N}=\mathbf{6 / 2 1 8})\end{array}$ & $\begin{array}{c}\text { Femoral } \\
(\mathbf{N}=\mathbf{2 3 / 1 5 3})\end{array}$ \\
\hline Event & & \\
$\quad$ Infection & $2(33.3 \%)$ & $10(43.4 \%)$ \\
Poor healing & $2(33.3 \%)$ & $8(34.8 \%)$ \\
Hematoma & $1(16.7 \%)$ & $1(4.3 \%)$ \\
Lymphoid leakage & $1(16.7 \%)$ & $4(17.4 \%)$ \\
Intervention & & \\
Washout & $3(50 \%)$ & $6(26.1 \%)$ \\
Vacuum-assisted device & $2(33.3 \%)$ & $6(26.1 \%)$ \\
Wet dressing only & $1(16.7 \%)$ & 0 \\
Repair of infected artery & 0 & $1(4.3 \%)$ \\
Closure with muscle flap & 0 & $11(47.8 \%)$ \\
\hline
\end{tabular}

Values are expressed with $\mathrm{n}(\%)$. *This patient also required muscle flap.

time to establish AX cannulation compared with FA cannulation, but it takes 30 to 45 minutes to start VAECMO from skin incision, which seems an acceptable time required not to delay an initiation of circulatory support. In the present study, there were significantly less cannulation-related complications with AX access, such as limb ischemia, switch to another arterial site, and wound complication represented by infection. As we observed, it is difficult to eliminate the incidence of cannulation-related leg ischemia after FA cannulation even with the use of a smaller arterial cannula (15 or 17 Fr), or high rate of antegrade limb perfusion. ${ }^{4,5}$ Therefore, AX cannulation is especially useful for patients at risk of leg ischemia, such as those with PVD, diabetes, or smokers, and clinical signs of ongoing leg ischemia before VA-ECMO insertion. Often in acute cardiogenic shock, leg ischemia may result from low flow with less pulsatility; from vasoconstriction, due to high-dose vasopressor use; or from other mechanical support devices inserted via the FA, such as an intra-aortic balloon pump, or Impella left ventricular assist device (Abiomed, Danvers, Mass). ${ }^{3,5,10}$ As in most procedures, surgical technique is important for successful AX cannulation. In the present study, although bleeding was the most common complication of $\mathrm{AX}$ cannulation (15\%), the incidence had improved to $4.0 \%$ over the past 3 years (January 2017 to October 2019) with meticulous surgical technique and diligent management of pump speed. It is important to achieve complete hemostasis at the graft-to-AX anastomosis by placing additional stitches as necessary and sealing needle holes with BioGlue before initiating VA-ECMO; it is difficult to control bleeding once the anastomosis is pressurized. Minimizing pressure on the anastomosis also helps to prevent bleeding, and we have found that pump flows of 1.5 to $2.2 \mathrm{~L} / \mathrm{min} / \mathrm{m}^{2}$ generally provide adequate support while reducing line pressure.
TABLE 8. Multivariate analysis of risk factor for cannulation-site wound complication

\begin{tabular}{|c|c|c|c|}
\hline & & $\begin{array}{c}\text { Odds ratio } \\
(95 \% \text { confidence }\end{array}$ & \\
\hline & Coefficient & interval) & $P$ value \\
\hline Femoral cannulation & 2.18 & $8.8(3.1-25.1)$ & $<.001$ \\
\hline PGF after heart transplant & 1.50 & $4.5(1.8-11.4)$ & .001 \\
\hline
\end{tabular}

$P G F$, Primary graft failure.

Cannulation wound complications are serious adverse outcomes that are associated with longer hospital stay, greater cost, and greater mortality, especially after heart transplantation due to immunosuppression, drug-induced diabetes, and preoperative low output status. ${ }^{12-18}$ Salna and colleagues ${ }^{15}$ reported that a cutdown procedure is a risk factor for developing FA wound complications in patients undergoing heart transplant. In the present study, arterial de-cannulation was performed by a cutdown technique, as we believed it would result in fewer vascular complications. Conservative management of groin wounds, including vacuum-assisted closure, lead to chronic infection and poor healing based on our experiences. Therefore, we had a low threshold to use a sartorius flap closure, especially for post-transplant patients, and thus the rate of Sartorius muscle flap closure in this study $(47.8 \%)$ was greater than other studies $(16 \%){ }^{12} \mathrm{We}$ currently use AX cannulation for all patients with PGF who need VA-ECMO after heart transplant, to avoid FA wound complications. A recent study reported that decannulation using a percutaneous closure device significantly reduces the incidence of groin wound complications for VA-ECMO in patients undergoing lung transplant. ${ }^{19}$ Although percutaneous closure devices are usually used for short-term procedures and placed before cannulation, they can be placed at the time of cannula removal. ${ }^{20}$ If this technique can be performed reproducibly without vascular complications, it could reduce the incidence of groin infection after femoral cannulation.

Stroke is a devastating complication of VA-ECMO, with reported rates of $5.0 \%$ to $17.4 \%$ for FA cannulation, ${ }^{2,12,13}$ and 1 study showed a greater rate of stroke with FA versus AX cannulation $(19.3 \%$ vs $6.2 \%){ }^{7}$ In our series, the overall cerebrovascular accident rate including stroke did not significantly differ between cannulation sites. This was probably because the etiology of stroke was not only associated with an arterial cannulation site but also other factors such as age, cerebrovascular disease, atrial fibrillation, left ventricular function, and the indication for VA-ECMO.

We should note several limitations of this study. (1) This was a retrospective, relatively small, single-center study. (2) 
TABLE 9. Preoperative characteristics of patients with primary graft failure after heart transplant

\begin{tabular}{|c|c|c|c|c|}
\hline & PGF $(\mathbf{N}=51)$ & Axillary $(\mathrm{N}=28)$ & Femoral $(\mathbf{N}=\mathbf{2 3})$ & $P$ value \\
\hline Age, y & $58(49-63)$ & $59.5(55.5-63)$ & $55(46-61.5)$ & .062 \\
\hline Male & $41(80.4 \%)$ & $23(82.1 \%)$ & $18(78.3 \%)$ & .728 \\
\hline Body surface area, $\mathrm{m}^{2}$ & $2.0(1.8-2.2)$ & $2.0(1.8-2.1)$ & $2.0(1.8-2.2)$ & .835 \\
\hline Body mass index, $\mathrm{kg} / \mathrm{m}^{2}$ & $27.8(25.1-32.0)$ & $28.5(26.8-33.4)$ & $27.5(24.9-30.8)$ & .394 \\
\hline Nonischemic cardiomyopathy & $38(74.5 \%)$ & $23(82.1 \%)$ & $15(65.2 \%)$ & .168 \\
\hline Redo sternotomy & $33(64.7 \%)$ & $19(67.9 \%)$ & $14(60.9 \%)$ & .603 \\
\hline Diabetes mellitus & $20(39.2 \%)$ & $13(46.4 \%)$ & $7(30.4 \%)$ & .244 \\
\hline Hypertension & $30(58.8 \%)$ & $20(71.4 \%)$ & $10(43.5 \%)$ & .044 \\
\hline Cerebrovascular disease & $5(9.8 \%)$ & $3(10.7 \%)$ & $2(8.7 \%)$ & 1.00 \\
\hline Peripheral vascular disease & $3(5.9 \%)$ & $2(7.1 \%)$ & $1(4.3 \%)$ & 1.00 \\
\hline Hemodialysis & $5(9.8 \%)$ & $3(10.7 \%)$ & $2(8.7 \%)$ & 1.00 \\
\hline Ejection fraction, $\%$ & $21(15-30)$ & $23(16-30.5)$ & $20(15-25)$ & .794 \\
\hline Intra-aortic balloon pump & $16(31.4 \%)$ & $9(32.1 \%)$ & $7(43.8 \%)$ & .896 \\
\hline
\end{tabular}

Values are expressed with $\mathrm{n}(\%)$ or mean \pm standard deviation (median). $P G F$, Primary graft failure.

Baseline characteristics were not homogeneous between the $\mathrm{AX}$ and FA groups, including a greater rate of pre-ECMO cardiopulmonary resuscitation in the FA group, and that of PVD in AX group which could affect the cannulation strategy. (3) The sample size and number of adverse events precluded propensity score matching, which may have corrected for the difference in patient characteristics between groups, but not completely.

In conclusion, the overall outcomes of both $\mathrm{AX}$ and FA cannulations were favorable. AX cannulation may be considered as an alternative for patients in cardiogenic shock, especially with limited groin access, severe PVD, and PGF after heart transplant. Use of 2 different arterial cannulation sites confers a more versatile cannulation strategy to establish VA-ECMO and provides patient-specific management in order to improve overall outcomes.

\section{Conflict of Interest Statement}

The authors reported no conflicts of interest.

The Journal policy requires editors and reviewers to disclose conflicts of interest and to decline handling or reviewing manuscripts for which they may have a conflict of interest. The editors and reviewers of this article have no conflicts of interest.

TABLE 10. Subanalysis of patients with PGF after heart transplant

\begin{tabular}{|c|c|c|c|c|}
\hline & PGF $(\mathbf{N}=51)$ & Axillary $(N=28)$ & Femoral $(\mathbf{N}=\mathbf{2 3})$ & $P$ value \\
\hline Cerebrovascular accident & $2(3.9 \%)$ & $1(3.6 \%)$ & $1(4.3 \%)$ & 1.00 \\
\hline Prolonged ventilation, $\geq 7 \mathrm{~d}$ & $22(43.1 \%)$ & $13(46.4 \%)$ & $9(39.1 \%)$ & .601 \\
\hline Renal-replacement therapy & $16(31.4 \%)$ & $8(28.6 \%)$ & $8(34.8 \%)$ & .634 \\
\hline Cannulation site bleeding & $3(5.9 \%)$ & $1(3.6 \%)$ & $2(8.7 \%)$ & .860 \\
\hline Cannulation-related limb ischemia & 0 & 0 & 0 & 1.00 \\
\hline Cannulation site wound complication & $10(19.6 \%)$ & $1(3.6 \%)$ & $9(39.1 \%)$ & .005 \\
\hline Length of ECMO support, $d$ & $6(4-8)$ & $6(4.5-7.5)$ & $6(4-10)$ & .633 \\
\hline Survival to discharge & $41(80.4 \%)$ & $22(78.6 \%)$ & $19(82.6 \%)$ & .994 \\
\hline
\end{tabular}




\section{Axillary Artery Cannulation for Veno-Arterial Extracorporeal Membrane Oxygenation Support in Cardiogenic Shock}

\section{Patients \& Method \\ VA-ECMO: Veno-Arterial Extracorporeal Membrane Oxygenation}

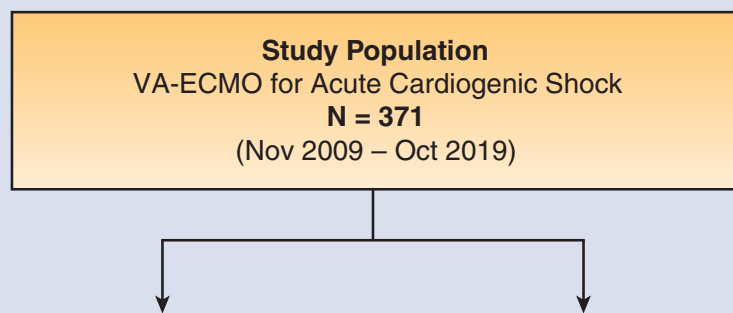

Axillary Artery ECMO $\mathrm{N}=\mathbf{2 1 8}$

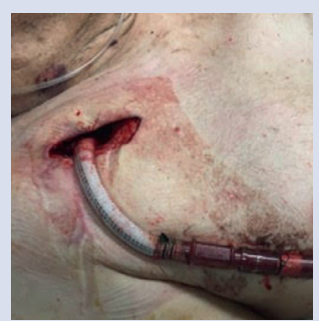

vs

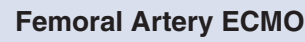

$\mathrm{N}=153$

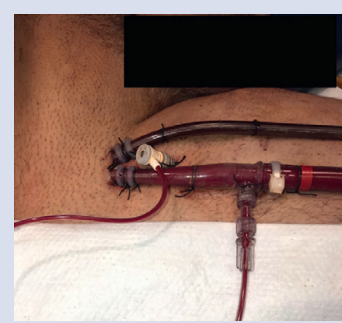

Endpoints

- Hospital mortality

- Cannulation related complications

1. Cannulation side limb ischemia

2. Bleeding

3. Wound complication (infection, poor healing, surgery)

4. Switch of arterial cannulation site (e.g. femoral to aorta)

\section{Results}

Axillary

$60.6 \%$

Survival to Discharge

Femoral

$56.9 \%$

Cerebrovascular Accident

$12.4 \%$

$10.5 \%$

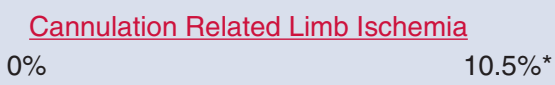

Switch of Arterial Cannulation Site

$4.6 \%$

$14.4 \%$ *

Cannulation Related Wound Complication

$2.8 \%$

$15 \% *$

Cannulation Site Bleeding

$15.1 \%$

$17 \%{ }^{*} P<.001$

Subgroup: Primary graft failure after heart transplant

Axillary $(\mathrm{N}=28) \quad$ Femoral $(\mathrm{N}=23)$

Cannulation Related Wound Complication

$3.6 \%$

$39.1 \% *{ }^{*} P<.001$

Implications: Axillary artery cannulation can be safe and effective alternative of femoral artery cannulation

FIGURE 2. A total of 371 patients who were supported with VA-ECMO for cardiogenic shock were compared based on the arterial cannulation site: axillary artery $(\mathrm{n}=218)$ versus femora artery $(\mathrm{n}=153)$. The outcomes were similar with regard to in-hospital outcomes, including survival to discharge $(60.6 \%$ vs $56.9 \%$ ), cerebrovascular accidents ( $12.4 \%$ vs $10.5 \%)$, and cannulation-related bleeding $(15.1 \%$ vs $17 \%)$. The incidence of limb ischemia related to VAECMO cannulation ( $0 \%$ vs $10.5 \%)$, the need to switch the cannulation site ( $4.6 \%$ vs $14.7 \%)$, and wound complications (WC; $2.8 \%$ vs $15 \%)$ including infection and additional procedure were significantly higher in the FA group $(P<.001)$. In sub-group analysis among PGF patients, WC were more prevalent in FA cannulation $(3.6 \%$ vs $39.1 \%, P=.001)$.

\section{References}

1. Extracorporeal Life Support Registry Report. Available at: https://www.elso.org/ Registry/Statistics/InternationalSummary.aspx. Accessed July 8, 2020.

2. Cheng R, Hachamovitch R, Kittleson M, Patel J, Arabia F, Moriguchi J, et al. Complications of extracorporeal membrane oxygenation for treatment of cardiogenic shock and cardiac arrest: a meta-analysis of 1,866 adult patients. Ann Thorac Surg. 2014;97:610-6.

3. Ohira S, Kawamura M, Ahern K, Cavarocchi N, Hirose H. Aggressive placement of distal limb perfusion catheter in veno-arterial extra corporeal membrane oxygenation. Int J Artif Organs. 2020;43:796-802.

4. Bisdas T, Beutel G, Warnecke G, Hoeper MM, Kuehn C, Haverich A, et al. Vascular complications in patients undergoing femoral cannulation for extracorporeal membrane oxygenation support. Ann Thorac Surg. 2011;92: 626-31.

5. Takayama H, Landes E, Truby L, Fujita K, Kirtane AJ, Mongero L, et al. Feasibility of smaller arterial cannulas in venoarterial extracorporeal membrane oxygenation. J Thorac Cardiovasc Surg. 2015;149:1428-33.

6. Hysi I, Fabre O, Renaut C, Guesnier L. Extracorporeal membrane oxygenation with direct axillary artery perfusion. J Card Surg. 2014;29:268-9.

7. Chamogeorgakis T, Lima B, Shafii AE, Nagpal D, Pokersnik JA, Navia JL, et al. Outcomes of axillary artery side graft cannulation for extracorporeal membrane oxygenation. J Thorac Cardiovasc Surg. 2013;145:1088-92.
8. Gass A, Palaniswamy C, Aronow WS, Kolte D, Khera S, Ahmad H, et al. Peripheral venoarterial extracorporeal membrane oxygenation in combination with intra-aortic balloon counterpulsation in patients with cardiovascular compromise. Cardiology. 2014;129:137-43.

9. Tang GH, Malekan R, Kai M, Lansman SL, Spielvogel D. Peripheral venoarterial extracorporeal membrane oxygenation improves survival in myocardial infarction with cardiogenic shock. J Thorac Cardiovasc Surg. 2013;145:e32-3.

10. Tanaka D, Hirose H, Cavarocchi N, Entwistle JW. The impact of vascular complications on survival of patients on venoarterial extracorporeal membrane oxygenation. Ann Thorac Surg. 2016;101:1729-34.

11. DeRoo SC, Takayama H, Nemeth S, Garan AR, Kurlansky P, Restaino S, et al Extracorporeal membrane oxygenation for primary graft dysfunction after heart transplant. J Thorac Cardiovasc Surg. 2019;158:1576-84.

12. Sutter R, Tisljar K, Marsch S. Acute neurologic complications during extracorporeal membrane oxygenation: a systematic review. Crit Care Med. 2018;46: 1506-13.

13. Mariscalco G, Salsano A, Fiore A, Dalén M, Ruggieri VG, Saeed D, et al. Peripheral versus central extracorporeal membrane oxygenation for postcardiotomy shock: multicenter registry, systematic review, and meta-analysis. J Thorac Cardiovasc Surg. 2020;160:1207-16.e44.

14. Glorion M, Mercier O, Mitilian D, De Lemos A, Lamrani L, Feuillet S, et al. Central versus peripheral cannulation of extracorporeal membrane oxygenation 
support during double lung transplant for pulmonary hypertension. Eur J Cardiothorac Surg. 2018;54:341-7.

15. Salna M, Takayama H, Garan AR, Kurlansky P, Farr MA, Colombo PC, et al. Incidence and risk factors of groin lymphocele formation after venoarterial extracorporeal membrane oxygenation in cardiogenic shock patients. J Vasc Surg. 2018:67:542-8.

16. Mehdiani A, Immohr MB, Boettger C, Dalyanoglu H, Scheiber D, Westenfeld R, et al. Extracorporeal membrane oxygenation after heart transplantation: impact of type of cannulation. Thorac Cardiovasc Surg. February 8, 2020 [Epub ahead of print].

17. Pellenc Q, Girault A, Roussel A, Aguir S, Cerceau P, Longrois D, et al. Preclosing of the femoral artery allows total percutaneous venoarterial extracorporeal membrane oxygenation and prevents groin wound infection after lung transplantation. Eur J Cardiothorac Surg. 2020;58:371-8.
18. Zimpfer D, Heinisch B, Czerny M, Hoelzenbein T, Taghavi S, Wolner E, et al Late vascular complications after extracorporeal membrane oxygenation support. Ann Thorac Surg. 2006;81:892-5.

19. Keebler ME, Haddad EV, Choi CW, McGrane S, Zalawadiya S, Schlendorf KH, et al. Venoarterial extracorporeal membrane oxygenation in cardiogenic shock. JACC Heart Fail. 2018;6:503-16.

20. Hwang J-W, Yang JH, Sung K, Song YB, Hahn J-Y, Choi J-H, et al. Percutaneous removal using Perclose ProGlide closure devices versus surgical removal for weaning after percutaneous cannulation for venoarterial extracorporeal membrane oxygenation. J Vasc Surg. 2016;63:998-1003.e1.

Key Words: axillary artery, veno-arterial extracorporeal membrane oxygenation, cannulation-related complication 